International Journal of English Literature and Social Sciences
Vol-7, Issue-1; Jan-Feb, 2022
Journal Home Page Available: $\underline{\text { https://ijels.com/ }}$
Journal DOI: $10.22161 /$ ijels

Peer-Reviewed Journal

\title{
Problems of Scientific Translation in Electronic Correspondence Between Iraqi and Foreign Users in Light of the Corona Virus Pandemic
}

\author{
Ayah Ali Salim
}

Assistant Lecturer, Department of English / Al-Nisour University College, Iraq / Baghdad

Received: 11 Dec 2021; Received in revised form: 25 Jan 2022; Accepted: 06 Feb 2022; Available online: 11 Feb 2022 (C)2022 The Author(s). Published by Infogain Publication. This is an open access article under the CC BY license (https://creativecommons.org/licenses/by/4.0/).

\begin{abstract}
With the beginning of the twenty-first century, it has become clear that the era of technology and globalization is loading. Technological advances set foot in the field of literature through translation. The translation is the transforming mediator between languages, which helps people from all over the world understand each other. This work studies the translating problems of electronic correspondence from Arabic to a foreign language.

This study hypothesizes that:

1. The discussed examples analyze all the vocal faults, ambiguity, and incorrectness of the translation generally.

2. This work will be understandable for all the readers, not only for the linguistic experts, except for the IPA transcription.
\end{abstract}

This study is limited to the problems, which relate to the technical and scientific terms, not to the literary ones. The most commonly used translator is Google unless another is mentioned.

The procedures of this study are:

1. Identifying the electronic correspondence.

2. Discussing why is Arabic not an easy language to translate

3. Showing the common and general problem of translating

a. Discussing the syntactic problems of translating.

b. Discussing the meaning or style issues.

c. Displaying the morphology and phonology misuses.

4. Discussing Specific problems of translation

5. Technical problems.

6. Suggested Solutions.

Keywords - Technology, Translation, Electronic Correspondence, IPA Transcription, Translating Problems.

\section{INTRODUCTION}

With the openness and convergence that has occurred, technology's interest in translation between different languages has become inevitable. Before that, this task was committed only to the superior human who knows multiple languages. Several meetings and conferences, especially diplomatic ones, were attended by translators between two conversing partners, which increases the duration of the event and often puts translators in embarrassing situations due to many problems, especially in technical matters, Akan et al. (2019:58). 
Nowadays, multiple translator applications are within reach, whether through mobile applications or search engines. Moreover, several technology companies have issued electronic headphones placed in the ear. They have a microphone, which receives the speech of the speaking person. Then, through a specific application on the mobile phone or tablet, or PC, the recipient determines the language to be translated into. After that, he can receive the speech automatically and simultaneously in his mother tongue through an electronic speaker and vice versa.

These electronic headphones gained wide attention from the beginning, but at the time of the outbreak of the Coronavirus, the need for them increased, and therefore their spread increased significantly. With the spread of its use, many technical and linguistic problems became more evident, especially in Iraq and the Arab countries. These problems split into general issues with translators translating into Arabic in general, specific problems with accents and the emergence of new terms, and technical problems with the performance of these electronic media.

This study aims to feature the problems of scientific translation in electronic correspondence, which Iraqi faces on the contact with foreign users in light of the Coronavirus pandemic. It also intends to suggest some strategies or solutions for some kinds of these problems.

The value of this study comes from the importance of its circumstances. The coronavirus imposed restrictions on travel and meetings; therefore, it gave rise to multiple losses for all the countries in the world. Therefore, making online conferences was a necessary solution. Thus, discussing these problems, especially for the Arab or Iraqi people, is helping to solve the issues, which may make them lose their opportunities to develop and succeed in their works or studies.

\section{WHAT IS THE ELECTRONIC CORRESPONDENCE FOR TRANSLATING?}

The electronic correspondence is an exceptional earphone that can be placed on the head or in the ears, operated by an application on a portable mobile device. They are also called CAI (Computer Aided Interpreter), Corpus (2018: 159). This earphone has a complex microphone, which contains a noise calling off to filter the other surrounding unwanted sounds. When the speaker says something, these words pass to a cloud, where they are processed and analyzed by AI (Artificial Intelligence) algorithms. After that, the translated words are sent to the user himself or anyone, who is accompanied in the conversation with a tiny delay. The translated language is determined by an application on the phone or any portable electronic mobile device. There are multiple kinds of these earphones that depend on the manufactured company. Almost all the earphones utilize Google translator and other famous and good translators. The difference between these correspondences is not only by the used translator and analyzed algorithms but also in the number of languages that can be translated between. The recent electronic earphones have at least 15 languages to switch between and the number is growing.

\section{THE PROBLEMS OF SCIENTIFIC TRANSLATION}

\section{1 general problems}

General problems are the common issues that face the translation from Arabic to other languages and vice - versa and relate to electronic correspondence. Akan, (2019:58) says the leading obstruction for this class of translating is the followed method, which could be specified as an automatic and to-the-letter method. It is an automatic translating method because the machine or the software does it. The to-the-letter manner means that it follows the word-to-word translation, unlike the human translator, who, besides using the prior method, can use the freestyle of translating, which could deliver the correct meaning of a sentence or speech to the receiver.The other obstructions or difficulties relate to grammar, word usage, and technic. Before listing the problems of translation, it is important to indicate why Arabic is a difficult language to translate? Then, the translation problems could be discussed more analytically, where the symbols between brackets are the IPA phonetic transcriptions of Arabic, AlHattami (2010:360).

\subsubsection{Why Arabic is not an easy language.}

The Arabic, Persian, and Hebrew languages are the only languages, which start the writings from the right side to the left. Arabic, unlike most other languages, has two basic categories of sentences: verbal and nominal sentences. The verbal sentence begins with the verb and is followed by the subject and the complement of the sentence, which is not found in other languages. Most other languages begin the sentence with the subject, which is followed by the verb and the complement of the sentence. This type of sentence is more like the nominal sentence in Arabic, except that the nominal sentence comes in several forms: SVC, SCV, and SA. The last form is the most interesting one because the two words or subjects following each other, where the second word describes or tellsabout the first one, are considered to be a 
sentence in Arabic, which gives errors in all other languages.

In addition, Arabic is a rich language and has several ways and forms to describe one meaning of the sentence. That thing is untrue for most other languages. The Arabic use special symbols are called علامات الإعراب('Calamat ulPiSrab’), which used to identify the word according to its location in the sentence or answering a specific question, which defines this word as subject, object, adjective, or .etc. While in English, these words have united forms and are identified by their constant and precise position, as the adjective must be in the front of the described subject or object, like 'an interesting topic' while in Arabic linguistic, the adjective follows the described one, like 'موضوع مثير للاهنمام' ('mawd'wSun muei:run lilpihtimam'). Now, several general problems are discussed in detail.

\subsubsection{Syntactic issues}

The Arabic language has a distinguishing of the gender of the subjects and words, while the English has one word for both genders: male and female, while in Russian they have male, female, and neutral.

Example: in Arabic: طالب، طالبة ('talib, taliba'), in English: a student ('stu:dnt'), in Russian: студент,студентка.

This problem will not face the foreigner in translating from Arabic to the other foreign language, but will the Iraqi or Arabian has a problem, especially in the case of mentioning some people he/she knows.

\subsubsection{Meaning issues}

\section{Passive:}

The two languages have the passive tense in the present and past. Unexpectedly, this tense forms an issue in translating from a foreign language to Arabic. The reverse is not always true. An example of translating an English sentence with passive tense in Arabic with two different translators: Google and Yandex.

English sentence: the prototype is developed by the engineer.

Google translate in Arabic: تم تطوير النموذج الأولي من

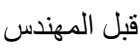

('Tammatat ${ }^{\varsigma}$ wi:ruannamu:ðadzialawwatiu min qibalialmuhandisi')

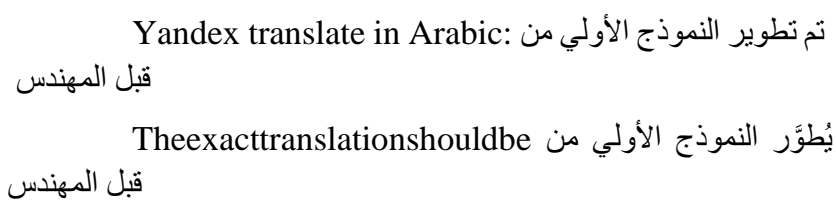

('Jut'awwarunnamu:ðadzualawwałiuminqibalialm uhandisi')
Foranexternalmonitor,

thisisnotabigdeal. Nevertheless, in the business and companies field, this makes a problem. The speaker did not mean that the prototype is ready and has been successfully developed, while the meaning is that he is working now on it. In general, the passive makes multiple problems for the translators; therefore, it is better to avoid using it as much as possible.

\section{Compound sentences}

Al-Muhiesen, (2019:325) defines compound sentences, which they are more used in academic and scientific writing. This sentence contains one essential purpose and several detailed explanations. These sentences will cause ambiguity in translating if they are not used in a proper and evident formulation. Besides, these complex sentences, the sequence of sentences or story may make an ambiguity. Especially when the story or long sentences have pronouns to refer to previous written subjects or objects. An example of this in translation from Arabic to English is:

\section{The Arabic compound text:}

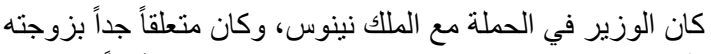

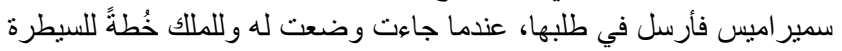

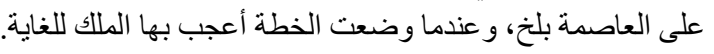

$$
\begin{aligned}
& \text { (' kanaalwazi:ru fi:lhamlatimaSaalmalikiNinusa, } \\
& \text { wa } \\
& \text { kana } \\
& \text { mutaSalliqandzidanbizawdzatihiSemiramis, } \\
& \text { faa?rsal fi: t`alabiha, Sindama dza?at wad`ạat } \\
& \text { lahu wa lilmaliki xut'`atan lissait`arati ৎala } \\
& \text { alৎas'imatiBalax, } \\
& \text { waSindamawad`aSatilxut`atu?uৎdzibabihaalmaliku } \\
& \text { lilyaya') }
\end{aligned}
$$

Its translation in English:

(The minister was on the campaign with King Ninos, and he was very attached to his wife Semiramis, so he sent for her, when she came, she put for him and the king a plan to control the capital, Balkh, and when the plan was drawn up, the king liked (it) very much).

The correct translation here will be ('the king liked her very much') for Semiramis not (it), as translated before, which refers to the plan.

Here, an example of mistranslating the technical sentences from English to Arabic are illustrated below:

English scientific sentence:The formulation of the wheel-rail contact problem is a complex task.

Google translation of this text in Arabic: إن صياغة مشكلة التلامس مع السكك الحديدية هي مهمة معقدة. 
('Inna s'i:ayata mujkilati attalamusi maS assekaki alhadi:di:ati hi: mahammatun muSaqadatun')

The right translation of this text is إن صياغة مشكلة النهة الاتصال بين العجلة و السكة الحديدية مهمة معقدة.

('Inna s'i:ayata mufkilati alPittis'ali baina alৎadzalati wassikati alhadi:di:ati mahammatun muSaqadatun')

The incorrect translation here is due to the writing style of this sentence, which contains abbreviations to avoid redundant long-term sentences in the English language. Without the abbreviations, the sentence above and the translation will be:

The reformulated English sentence:The formulation of the contact problem between the wheel and rail is a complex task

The translation of the reformulated sentence: تعد صياغة مشكلة التلامس بين العجلة و السكك الحديدية مهمة معقدة

(TuSaddu si:ayatu mufkilatu attalamusi bain al Sadzalati wassekaki alhadi:diati mahammatun muSaqadatun')

\subsubsection{Morphology issues:}

The form of the words may cause some problems in translating. As in Arabic, we use some symbols upper or lower some words to differentiate the usage of the word, like منتّج('muntids') in Arabic as a producer, and هنتَج 'muntad\}' as a product. Some languages like Russian and French use prefixes and suffixes to give different meanings for specific words. An example of this issue is shown below:

In English: the workers finish the final design. The producer is working now.

In Arabic: ينهي العمال التصميم النهائي. المنتج يعمل الآن

('Junhi: alৎummalu attas'mi:ma anniha?i: Almontidzu ja?malu al?ana')

As in the writing of this translation, nothing is wrong. Surprisingly, when the speaker of the translator says the translation, it reads المنتَج as ('almuntadz'), which is a product, unlike the meant word as المنتج ('almuntids'), who is the producer. The same problem does not have to be in translating from Arabic because it depends on the spelling of the word from Arabian.

\subsubsection{Phonological issues}

These kinds of problems concern the sounds, tones, and rhythms. Here, the Iraqi or any other Arabic accent will cause a big problem in translating, the same as misspelling from the other side of its language. To make an electronic correspondence, which may understand each Arabic accent correctly, demands an intelligent machine- learning algorithm, wide data storage, and costs a lot.Therefore, the spoken language needs to be Classical Arabic (pure language).The tones are essential to delivering the actual meaning and expression to the others, which is not evident in the translators of this kind. In addition, speaking in a slow rhythm is better to ensure a well understanding of the receiver and well interpreting and analyzing from the electronic translators.

\subsubsection{Metaphors}

Metaphors are implicit expression methods of speech. Its meaning is not understood literally, but it explains specific ideas more elegantly and colourfully. Therefore, the spoken language needs to be Standard Arabic.The use of metaphors in Arabic or other languages poses a problem for the translator and the other speaker. Here, two examples of using metaphors in English and the literal translation, which will be used by the electronic correspondence, and the actual meaning of these metaphors in Arabic.

Metaphor in English: Every cloud has a silver lining.

Sل Lل سحابة لها بطانة : فضية

('Kullu safiabatin laha bit'anatun fid'i:atun')

The actual meaning in Arabic: إن مع العسر يسراً

('Pinna maSa aluSsri jusran')

Metaphor in English:developing designs is not a piece of cake. قطعة من الحلوى

Literal translation in Arabic: تطوير التصاميم ليس alfalwa')

('tat'wi:ru attas'ami:mi laisa qitৎatan min

The actual meaning in Arabic: تطوير التصاميم ليس بالأمر السهل

('tat'wi:ru attas'ami:mi laisa bilamri alsahli')

\subsubsection{Several meanings of words}

It will be great for the translators if each word in every language has only meaning and usage. Unfortunately, this is not true for almost all languages in the world. Such words, which have one meaning, are called 'ممنوع من الصرف' ('mamnouSun mina s'arf') in Arabic linguistics, means forbidden to exchange in English. The other words have several forms and can be in different places in the sentence. Some words in Arabic can be separated into parts and will have different meanings, are called alliteration, 'الجناس' ('aldzinas') which are the similarities between two words in the number of same letters and their order. There is another kind of alliteration. 
However, it is not the point of interest here. The alliteration widely exists in the poetry and the verses from the book (Al-Quran). In Russian, for example, the word пожалуйста have two meanings that depend on its location in the text. The first meaning is as the Arabic term ('law samafit') and the English word 'Please', and the second as the Arabic idiom على الرحب و السعة'Pala arrahbi wassi9a') and 'any time', or 'you are welcome' in English.

\subsection{Specific problems:}

\subsubsection{New technical words}

The specific problems are the ones that relate to the entrance of the new words and idioms in the languages. It is certain that with this unstoppable technological revolution and the extraordinary situations, imposed by the spread of Coronavirus, new terms, took their way to our languages. Nowadays, it is necessary to be a follower of technical developments to be a member of this era. New English terms enter the Arabic language as they are without any transferto their accordance in Arabic. Therefore, this demands more responsibility to the Arabian or Iraqi to have been in touch with all the recent in his field.

The problems in translating the technical texts are numerous. The gap between the technological evolution between Arab and western and eastern countries, no doubt, is noticeable big. Therefore, there are multiple issues in translating the technical terminology due to multi fields of science. Here, some of the mistranslations in different sciences are illustrated below.

\section{Medical Field}

The medical field is considered the toughestfield by its complex compound terminology. It is not one hundred per cent of non-truth saying that it is the most difficult to translate and find or create the terminology synonyms in Arabic. Below, an example of English medical text about coronavirus is translated to Arabic and discussed.

Example:Specific genes are present in all the coronaviruses in ORF1 downstream regions, which encode the proteins for nucleocapsid, viral replication, and spike formation. On the outer surface of the coronaviruses, there are glycoprotein spikes that facilitate the entry and attachment of the virus to the host cells.

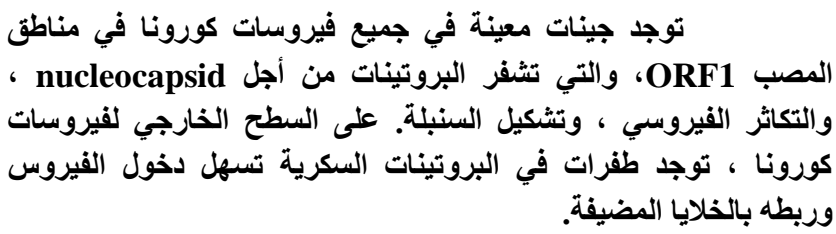

When listening to the spoken interpretation of this translation, multiple notes are declared, unclear translation for the abbreviations of scientific technology in Arabic, as in (ORF1). Moreover, misspelling the verbs which need a tighten (ङ) in tone to deliver its correct meaning, as in (تشفّر). In addition, incorrect translation of term (spike formation) as (تشكيل السنبلة).Finally, the missing synonym of (nucleocapsid) in Arabic.

\section{Geographic}

Geography is the science of studying lands, features, and the phenomena of the Earth and other planets. Geography also has complex terms, which cause ambiguity of translation. A simple example of that is discussed as in the following:

Example:About 4.5 billion years ago, gravity coaxed Earth to form from the gaseous, dusty disk that surrounded our young sun. Over time, Earth's interior-which is made mostly of silicate rocks and metals - differentiated into four layers.

\section{Translation results:}

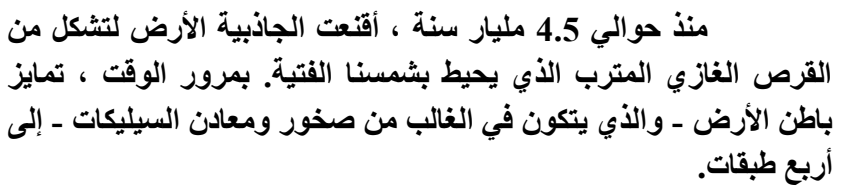

('munđu hawalai arbaৎa fas'ila xamsa miliari sanatin, aqnaSataldzađibi:atualard'litufakkila mina alqursialyazii: almutarabiallađi: jufit`ubifamsina alfitiati. Bimurori alwaqt, tamaiuzu bat ${ }^{\varsigma}$ ini alard ${ }^{\varsigma}$ wallađi jatakawwanu fi: alyalibi min s'uxo:ri wa maSadini assilikati - Pila ParbaSi t'abaqatin.')

\section{The exact translation:}

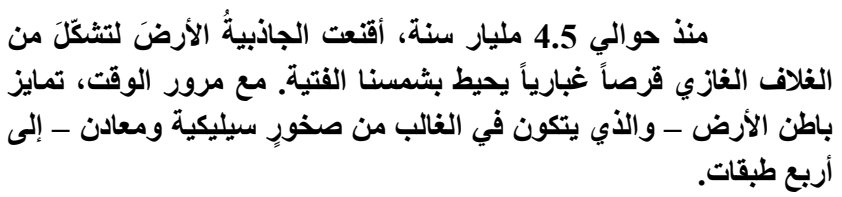

The problems relate to the followed literal wayin the translation and the style of speech. The places of

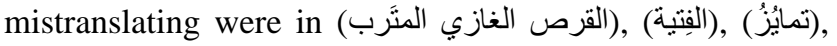
and (صخور ومعادن السيليكات). The problems inform the importance of the punctuations in speech, which could be formulated by the rhythm of speech and consider the linguistic rules of other languages.

There are numerous examples of incorrect translations in the technical fields, which relate to the differences in structures between the languages, the gaps between the technical levels of several countries, and the style of speech. 


\subsubsection{Individual problems}

The other issue, which belongs to the specific ones, is the problem relates to the human himself, the speaker or the listener in this case. In more detail, for the Arabs, The Arabs have two characteristics in their speech, multilingual and bilingualism. As for multilingual, it means that a person speaks two different languages at the same time, and this is what happens in Arab countries in general. Arabic is used in social interactions and English in work and study. These two languages are complete opposites, but the Arab combine them. Especially in Iraq, the English words invade the spoken language in ordinary life. Moreover, in Lebanon and the western Arab countries, the French language is also involved in real-life and study.

The other kind is to mention here is bilingualism, meaning that a person speaks two different dialects of the same language! Classical and colloquial dialect. Even more, one country may have more than one dialect! Saudi Arabia, for example, combines the Gulf dialect in some of its regions, the Hijazi dialect in the zones of Hejaz and Tehama, and the Najdi dialect in the Najd region. Egypt also combines different dialects, as well as the Levant and others. Iraqi also have more than one dialect. The main reason for that is the difference in nature and climate all over the Arab country. These reasons make an additional weight on the Arabian, who wants to speak with foreigners. They talk, in real-life, in a language (colloquial), which is widely different from the Standard and world announced one.

\subsubsection{Cultural and moral issues}

The mistranslation may cause incorrect understanding or behaves in some cases. This wrong translation occurs in all languages because of the incorrect spelling of some words and the different meanings of one word. The translator, in ambiguous cases, takes the most popular use of this word and neglects the others.

\subsection{Technical problems}

The technical problems depend on the electronic correspondence, which significantly relates to the kind of the followed algorithms, used translators, the quality of the components, the capability of translating more languages, the correctness of the results, and the adaptability of these pieces.

Nowadays, a big competition occurs between technology companies to develop electronic interpreters, which can translate many languages and have emphasized AI algorithms to analyze the speech, understand it, and retranslate it to the other language more understandably and conveniently, simulating the human technic.

\section{SUGGESTED SOLUTIONS}

Since there are multiple problems, several suggested solutions, which may enhance the translating or reduce the faults and ambiguity of translating, are listed as follows:

1. The first and most important suggested solution is emphasizing the way of talking, as mentioned before. This thing states a slow and understandable rhythm of speaking with a correct character output and talking in the Standard language.

2. Having the desire to follow the recent developments and achievements and learning to speak in different languages is a key to solving translation problems.

3. Some problems occur due to old and unqualified used tools. Therefore, using an upgraded and latest version of electronic correspondence is adequate for having less frequent issues.

4. Contributing and raising awareness in spreading the Standard Arabic language is vital. The bilingual and multilingual will destroy our national Arabic language. Therefore, saving the Arabic language is an obligation to rescue our existence.

\section{CONCLUSION}

Recently, many technical English words have invaded Arabic and many other languages. This invasion acts in the spoken and connecting language between adults. This problem will arise and spread without accountability and observation. The previously defined problems push us to strengthen our language and help to deliver it to the world correctly. No one can understand the Arabic language than the Arabs themselves. Therefore, taking part in emphasizing the translation between Arabic and other foreign languages is the responsibility of each native and educated Arabian.

\section{REFERENCES}

[1] Abu Ilayyan, Manar Fahmi Ibrahim. (2019). Difficulties that Jordanian translators encounter in translating technical texts and expressions from English into Arabic. (Master's theses Thesis and Dissertations Master). Middle East University, Jordan.

[2] Akan, Faruquzzaman and Karim, Md and Chowdhury, Abdullah. (2019) "An Analysis of Arabic - English Translation: Problems and Prospects". Advances in Language and Literary Studies Journal Vol. 10. P. 58. 
[3] Al-Hattami, Abdulghani. (2010) "A Phonetic and Phonological Study of the Consonants of English and Arabic”. Language in India Journal Vol. 10. PP. 242-365.

[4] Al-Muhiesen, Esra'A and Al-Ajrami, Muna. (2019) "Challenges in Translating Technical Texts". Dirasat: Human and Social Sciences Journal Vol. 46. PP. 322-328.

[5] Corpus Pastor, Gloria. (2018) "Tools for Interpreters": The Challenges that Lie Ahead". The University of Malaga. PP. 157-182.

[6] Doherty, Stephen. (2016) "The Impact of Translation Technologies on the Process and Product of Translation". International Journal of Communication Vol. 10. P. 969.

[7] Munday, Jeremy. (2009) the Routledge Companion to Translation Studies. The University of Leeds. Spain.

[8] Newmark, Peter (1982) Approaches to Translation. Pergamon Press Ltd. Oxford.

[9] Rasul, Sabir. (2016) "Translation Constraints and Procedures to Overcome them in Rendering Journalistic Texts". Journal of University of Human Development Vol. 2. PP. 402-419.

[10] Sigacheva, Natalya. Baranova, Alfiya. Vakhitova, Diliara. Gulkanyan Meri and Giananova Diliara. (2020) "Scientific Communication and Translation Problems with Synonyms, Antonyms, Homonyms in Construction Sphere". Kazan. IOP Conf. Ser.: Master. Sci. Eng. 890012211. 